\title{
Genetic and epigenetic alterations of myeloproliferative disorders
}

\author{
Jelena D. Milosevic $\cdot$ Robert Kralovics
}

Received: 24 October 2012/Revised: 27 November 2012/Accepted: 27 November 2012/Published online: 12 December 2012

(C) The Japanese Society of Hematology 2012

\begin{abstract}
The classical BCR-ABL negative myeloproliferative neoplasms (MPN) polycythemia vera, essential thrombocythemia, and primary myelofibrosis are clonal hematopoietic disorders characterized by excessive production of terminally differentiated myeloid cells. In MPN patients, the disease can progress to secondary myelofibrosis or acute myeloid leukemia. Clonal hematopoiesis, disease phenotype, and progression are caused by somatically acquired genetic lesions of genes involved in cytokine signaling, RNA splicing, as well as epigenetic regulation. This review provides an overview of point mutations and cytogenetic lesions associated with MPN and addresses the role of these somatic lesions in MPN disease progression.
\end{abstract}

Keywords Myeloproliferative disorder - Polycythemia vera Essential thrombocythemia $\cdot$ Primary myelofibrosis

\section{Introduction}

Myeloproliferative neoplasms (MPN) are characterized by clonal expansion of terminally differentiated myeloid cells. According to the 2008 WHO classification, MPNs include polycythemia vera (PV), essential thrombocythemia (ET), primary myelofibrosis (PMF), chronic myeloid leukemia

\section{J. D. Milosevic · R. Kralovics $(\square)$}

CeMM Research Center for Molecular Medicine of the Austrian

Academy of Sciences, Lazarettgasse 14, AKH BT25.3,

1090 Vienna, Austria

e-mail: rkralovics@cemm.oeaw.ac.at

\section{R. Kralovics}

Division of Hematology and Blood Coagulation,

Department of Internal Medicine I,

Medical University of Vienna, Vienna, Austria
(CML), chronic neutrophilic leukemia, mastocytosis, and chronic eosinophilic leukemia not otherwise specified, as well as unclassifiable MPN [1]. The first four disease entities are also known as "classical" MPNs. Since CML is characterized by the oncogenic fusion of the $B C R$ and $A B L$ genes, PV, ET, and PMF are commonly known as Philadelphia-chromosome negative or $B C R-A B L$ negative MPNs.

Despite their phenotypic diversity, all MPNs exhibit clonal hematopoiesis driven by acquired mutations. The most famous example of such a driver mutation is the $B C R-A B L$ fusion oncogene causing CML. The discovery of the $B C R-A B L$ fusion has made molecular diagnosis as well as therapeutic management of CML possible. In 2005, a somatic mutation in the $J A K 2$ gene was identified in the "classical" MPNs with similar significance as $B C R-A B L$ in CML. The MPN-associated JAK2 mutation (V617F) has been found in over $90 \%$ of $\mathrm{PV}$ cases and in about $50-60 \%$ of ET and PMF [2-5]. The V617F mutation is located in exon 14 of $J A K 2$, but various exon 12 mutations have also been described in PV [6, 7]. Mutational analysis of $J A K 2$ has greatly aided the diagnosis of the "classical" MPNs, and there are several Janus kinase 2 (JAK2) kinase inhibitors at various stages of clinical development for therapeutic management of MPN.

Since the discovery of $J A K 2$ mutations, much effort has been made to define other genetic lesions involved in disease pathogenesis, especially in JAK2-negative ET, PMF, and PV cases. These studies have identified a striking number of other somatic lesions predominantly targeting cytokine receptor signaling and regulation of gene expression [8, 9]. As MPN has at least three recognized disease stages (chronic phase, accelerated phase, and leukemic transformation) the role of somatic mutations in disease progression has been addressed by a number of 
studies. In general, the somatic mutations found in MPN patients can be functionally classified into three groups: (1) mutations providing clonal advantage but not inducing disease phenotypes; (2) mutations capable of inducing clonal growth as well as a disease phenotype; (3) mutations causing acute disease phenotypes, such as leukemia (Fig. 1). This review will provide a comprehensive overview of MPN-associated point mutations and cytogenetic lesions. Furthermore, we will address the role of these somatic lesions in MPN disease progression and discuss the challenges arising from the genetic complexity of MPN.

\section{Mutations of the JAK2 gene}

Janus kinase 2 is a member of a JAK family of tyrosine kinases, which additionally includes JAK1, JAK3, and TYK2. These proteins are characterized by four functional domains: FERM domain, SH2 domain, pseudokinase domain (JH2), and tyrosine kinase domain (JH1) [10]. The structure of the protein, which has two Jak homology domains $\mathrm{JH} 1$ and $\mathrm{JH} 2$, was the reason for this protein family to be named after the two-faced Roman god Janus. Although homologous to the tyrosine kinase domain, the $\mathrm{JH} 2$ domain lacks kinase activity and has been shown to act as a negative regulator of JAK protein kinase function [11]. The JAK proteins play important roles in the hematopoietic cell signaling induced by cytokines. Cytokine receptors, including the erythropoietin (EPOR), thrombopoietin (TPOR), and granulocyte colony-stimulating factor receptors (GCSFR), lack phosphorylation activity in their intracellular domain, and upon activation by ligand binding induce oligomerisation and phosphorylation of JAKs, which then phosphorylate further downstream targets (for example STATs) regulating transcription [12].

The JAK2 gene encoding JAK2 tyrosine kinase is located on chromosome 9p24. Following the observation that acquired uniparental disomy (UPD) of chromosome 9p is present in $30 \%$ of patients with PV [13], the gain-offunction somatic $J A K 2-\mathrm{V} 617 \mathrm{~F}$ mutation was discovered as the most prominent genetic aberration in patients with MPN [2-5]. In PV, $95 \%$ of the patients carry JAK2-V617F mutation, while in ET the frequency is $50-60 \%$, and in PMF $40-50 \%$ (Fig. 2). This mutation can also be found in other myeloid malignancies at lower frequencies.

The JAK2-V617F mutation affects the $\mathrm{JH} 2$ domain of the protein, abrogating its function and leading to constitutive activation of the kinase. In order to induce transformation and activate downstream targets, the activated kinase requires the coexpression of homodimeric cytokine receptors EPOR, TPOR, or GCSFR [14, 15]. Studies of mouse models have provided deeper insight into how one mutation can cause three different phenotypes. In mouse transplantation models the Jak2-V617F mutation causes erythrocytosis [3]. Further studies of Jak2-V617F knock-in mice showed that gene dosage has an effect on phenotype, which is closer to PV in cases of heterozygous expression of the mutant Jak2, while the homozygous mutation leads to a more severe phenotype and progression from PV to
Fig. 1 Model of disease initiation and progression in myeloproliferative neoplasms. Role of genetic lesions with different phenotypic effects

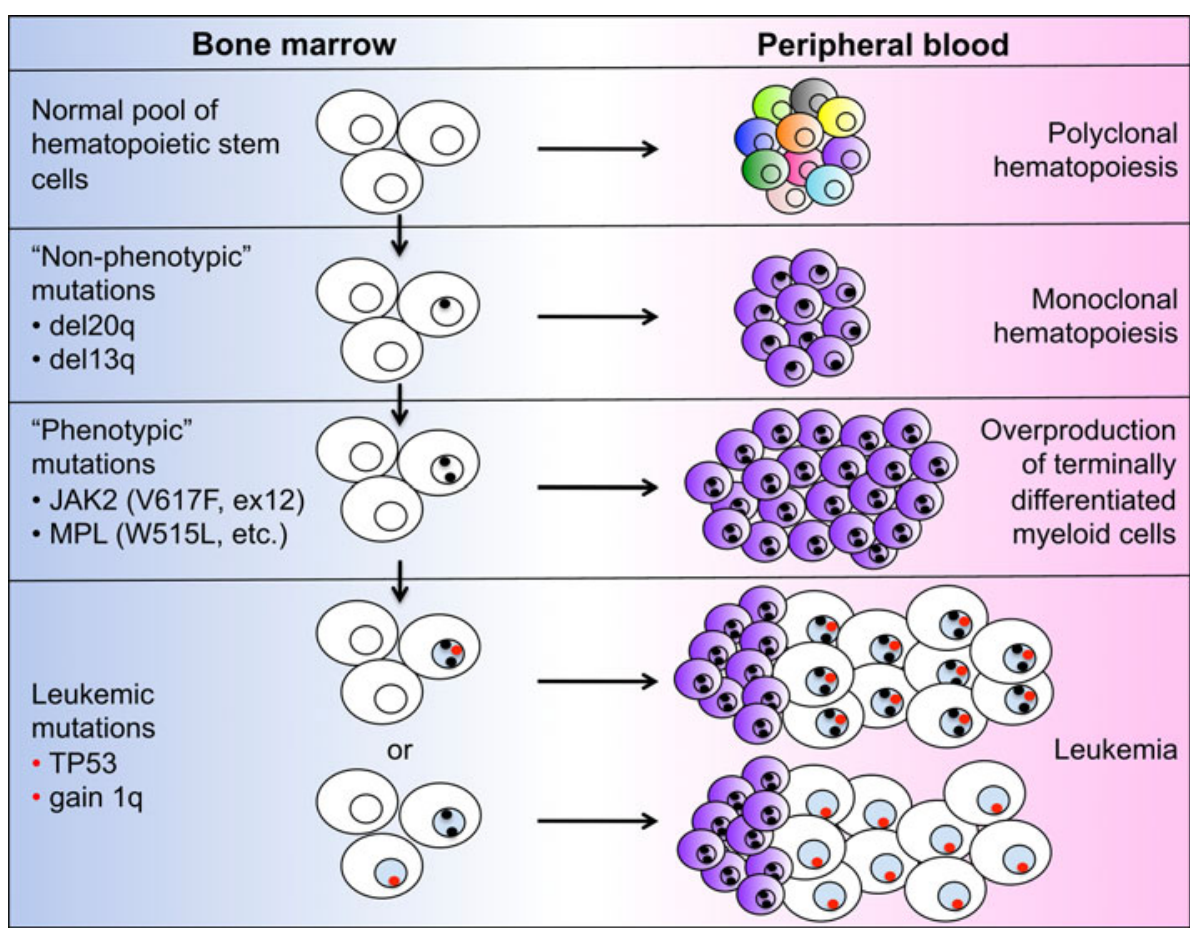


Fig. 2 Frequencies of mutations in commonly affected genes in patients during chronic myeloproliferative phase

$(\mathbf{a}-\mathbf{c})$ and acute leukemic phase (d) of the disease. $P V$

polycythemia vera, $E T$ essential thrombocythemia, $P M F$ primary myelofibrosis, $M P N$

myeloproliferative neoplasm, $A M L$ acute myeloid leukemia
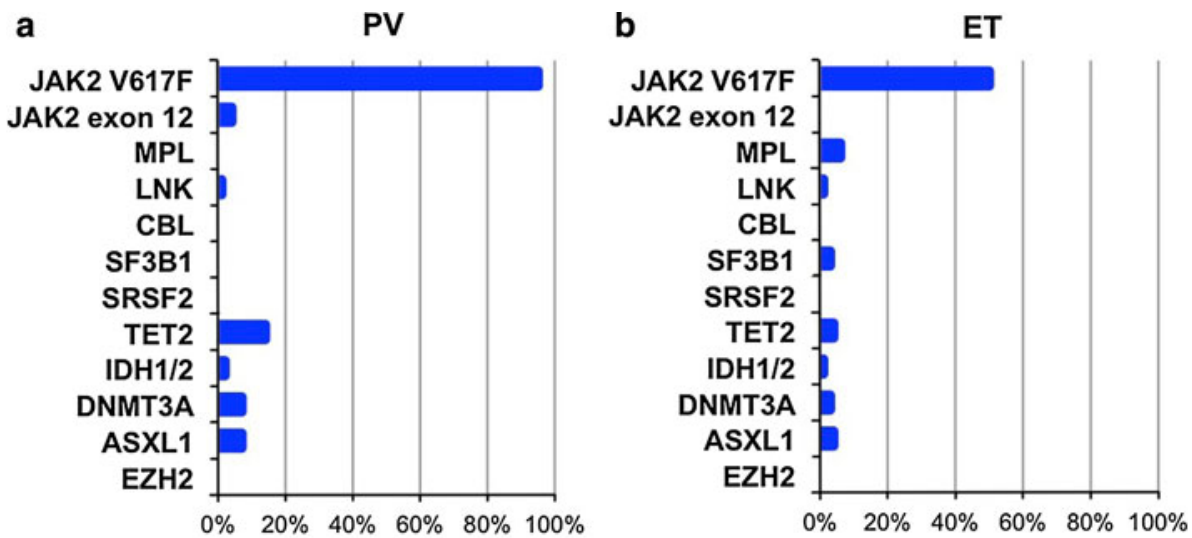

c

PMF

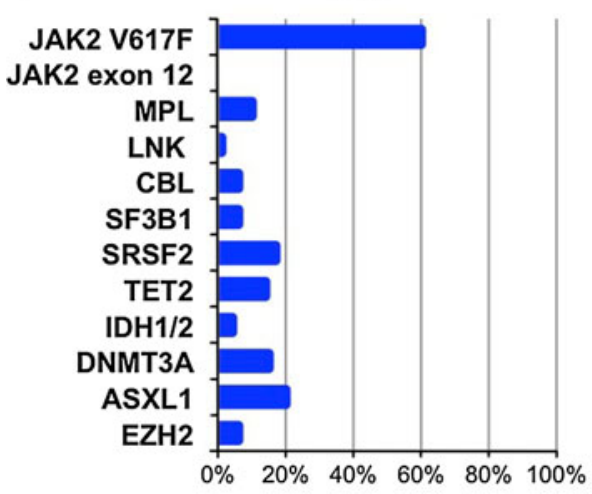

d

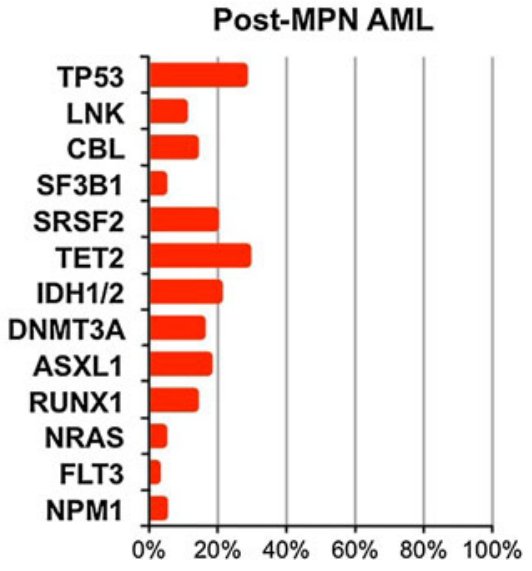

myelofibrosis [16]. Other mouse model studies yielded similar results, confirming that JAK2-V617F causes an MPN phenotype [17-21].

In PV, but not ET or PMF, a small percentage of JAK2V617F-negative patients carry mutations in exon 12 of the $J A K 2$ gene [6, 7]. Most exon 12 mutations target the K539 residue, with a similar functional consequence on the $\mathrm{JH} 2$ domain, leading to a myeloproliferative phenotype in a mouse bone marrow transplant model [7].

In addition to its prominent role in cytokine signaling, mutant JAK2 can act as an epigenetic regulator, mainly by phosphorylating histone $\mathrm{H} 3$ or an arginine methyltransferase PRMT5, in the nucleus. Phosphorylation of H3 at position Y41 inhibits the binding of heterochromatin protein $1 \alpha(\mathrm{HP} 1 \alpha)$, known to be involved in transcriptional repression, DNA repair and other cellular processes [22-24]. JAK2 mutants (V617F or K539L) display higher affinity for binding arginine methyltransferase PRMT5. The phosphorylation of PRMT5 by mutant JAK2 prevents its association with methylosome protein 50 (MEP50) in an arginine methylation protein complex and leads to decreased methylation of histones H2A and H4 [25]. It also seems to play an important role in erythroid differentiation and progenitor cell proliferation [25].
Mutations affecting the thrombopoietin receptor gene $M P L$

The proliferation and differentiation of megakaryocytes and development of platelets is regulated by thrombopoietin, which upon binding to its receptor encoded by the myeloproliferative leukemia virus oncogene $(M P L)$ induces signaling through the JAK-STAT pathway. Not long after the discovery of JAK2 mutations in MPN, somatic mutations affecting the exon 10 of $M P L$ were found in $9 \%$ of patients with myelofibrosis, who were $J A K 2-\mathrm{V} 617 \mathrm{~F}$ negative [26]. The mutation described was a gain-offunction substitution of tryptophan to leucine at codon 515, which was shown to lead to cytokine-independent growth and thrombopoietin hypersensitivity in the 32D, UT7, and $\mathrm{Ba} / \mathrm{F} 3$ cell lines due to constitutive phosphorylation of JAK2, STAT3, and STAT5 as well as of the ERK and AKT proteins [26]. Study of the thrombopoietin receptor protein structure revealed that the amino acid residue W515, which is affected by mutations, is located within the cytoplasmic juxtamembrane region of the protein, which prevents spontaneous activation of the receptor in the absence of ligand [27]. In mouse bone marrow reconstitution experiments, $M p l-W 515 \mathrm{~L}$ expression induced a PMF-like 
phenotype with thrombocytosis, leukocytosis, hepatosplenomegaly, and bone marrow fibrosis, leading to a fatal outcome.

Several other somatic mutations in $M P L$ were later found at lower frequency in MPN patients, affecting either the same amino acid, including W515K, W515A, W515S, W515R [28-30], or S505N, first described in familial thrombocytosis [31]. Exon $10 \mathrm{MPL}$ mutations account for up to $15 \%$ of $J A K 2$-V617F negative cases of ET and PMF [26, 28, 29, 32]. Studies of the clonal structure in $M P L-$ positive patients revealed that the MPL mutations arise early in the disease evolution, affecting progenitors of both myeloid and lymphoid lineages [33]. Amplification of $M P L$ mutations to homozygosity through mitotic recombination leading to acquired UPD of chromosome $1 \mathrm{p}$, as well as biallelic mutations has been reported in a number of patients [34-36].

\section{Mutations affecting $L N K$}

Mutations affecting $L N K(S H 2 B 3)$ are rare and were first described in patients with $J A K 2$-V617F negative MPN $[37,38]$. LNK is an adaptor protein known to be involved in the down-regulation of thrombopoietin-mediated signaling $[39,40]$. It inhibits the constitutive activity of JAK2V617F, as well as downstream MPL-W515L signaling [41, 42]. Lnk knockout mice develop an MPN phenotype, characterized by splenomegaly with marked fibrosis, due to accumulation of abnormal levels of erythrocytes, megakaryocytes, and B lymphocytes [43]. Mutations mainly affect exon 2, but can also be found throughout the gene. Mutations in $L N K$ were also described in context of disease progression in $9.8 \%$ of post-MPN acute myeloid leukemia (AML) cases [44]. However, two cases were also reported with $L N K$ mutations only during the chronic phase, not the leukemic phase of the disease. JAK2-V617F positive patients with $L N K$ mutations have also been reported, although the possibility of the presence of two different clones was not excluded [44]. SH2B protein family contains two members in addition to SH2B3, SH2B1, and $\mathrm{SH} 2 \mathrm{~B} 2$. A somatic mutation affecting $\mathrm{SH} 2 \mathrm{~B} 2$ was found in one case of post-MPN AML [45].

\section{Mutations of $C B L$}

Somatic mutations of $C B L$ have been described in a variety of myeloid malignancies, including AML, MPN, myelodysplastic syndromes (MDS), and others [46-51]. The $C B L$ gene is located at 11q23.3 and mutations show a strong association with acquired UPDs of chromosome 11q. Mutations in this gene are found in $6 \%$ of PMF patients, and rarely in ET and PV [50]. The CBL protein acts as a regulator of signal transduction, either as an adaptor protein or as an E3 ubiquitin ligase that can target cytokine receptors (EPOR, TPOR), tyrosine kinases (JAK2, ABL), and signaling adaptors (GRB2), leading to their proteasomal degradation [52, 53]. $\mathrm{Cbl}$ knockout mice show hyperproliferation, enhanced thrombopoietin sensitivity and STAT5 phosphorylation, and enhanced repopulating capacity of HSCs, but do not develop a malignant phenotype [54]. However, deletion of a related member of the CBL protein family, $C b l-b$, in addition to $C b l$ in HSC leads to an aggressive myeloid phenotype in mice [55], indicating that these two proteins may have a redundant function, although $C B L-B$ mutations are rarely found in patients and by themselves do not induce hematological disorders in mice. Mutations in $C B L$ mainly affect exons 8 and 9, encoding the ring finger domain and the adjacent linker region to the tyrosine kinase-binding domain of the protein [49-51]. The mutated CBL does not have E3 ubiquitin ligase activity, and is thought to act as a dominant negative, impairing the function of the wild-type CBL if present, as well as CBL-B [51]. In vitro studies of CBL mutants show that they exhibit cytokine-independent growth and prolonged activation of the FLT3 signaling $[46,51,56]$. Mice transplanted with transduced mutant $\mathrm{c}$ - $\mathrm{Cbl}$ bone marrow cells develop myeloproliferative disease, mastocytosis, and myeloid leukemia [57]. The $C B L$ mutations have been described during disease progression in $13 \%$ of post-MPN AML patients $[58,59]$. However, the prognostic value of $C B L$ mutations is unclear and will need to be evaluated in prospective studies.

\section{Mutations affecting the splicing machinery}

Mutations affecting various proteins involved in RNA splicing are common across all myeloid malignancies although they are predominantly found in MDS patients [60]. In MPN, they affect $9.4 \%$ of patients [60]. Several genes encoding the components of splicing machinery were found mutated in a mutually exclusive manner, such as SF3B1, SRSF2, U2AF1, ZRSR2, SF3A1 and others. $S F 3 B 1$ mutations are found in $4-6.5 \%$ of patients with PMF and $3 \%$ of patients with ET (Fig. 2), but no association with clinical features or other mutations has been clearly established although association with thrombotic events has been proposed [61-63]. As SF3B1 mutations show high specificity for MDS with increased ring sideroblasts ( $\sim 80 \%$ of the cases), it is not surprising that this feature has also been observed in MPN patients with this mutation [60]. Mutations affecting SRSF2 are found in $17 \%$ of patients with PMF and $18.9 \%$ of post-MPN AML and are associated with $I D H 1 / 2$ mutations ( $28 \%$ of SRSF 2 
mutated cases carry $I D H 1 / 2$ mutations in addition) [64, 65]. Analysis of paired samples from leukemic and chronic phases showed that SRSF2 mutations when present at transformation were also present during the chronic MPN phase of the disease [65]. These are associated with poor overall and leukemia-free survival $[64,65]$. SRSF2 mutations target predominantly the P95 residue of the protein either by point mutations or insertion/deletions $(\mathrm{P} 95 \mathrm{H}$, P95L, P95R, etc.).

Mutations affecting $U 2 A F 1$ and $Z R S R 2$ were reported at low frequencies $(\sim 2 \%)$ in MPN patients. The mechanism by which mutations in the splicing machinery lead to an impaired hematopoiesis is unclear. In vitro studies of U2AF1 mutants indicate that they are dominant negative, leading to aberrant splicing, inhibition of proliferation, and apoptosis induction [60].

\section{The role of epigenetic changes in MPN}

Regulation of transcription can be achieved through epigenetic mechanisms, which involve DNA and histone modifications. Methylation and hydroxymethylation of cytosines in DNA, as well as methylation, acetylation, and other modifications of histones, are the most common mechanisms of achieving transcriptional repression. These processes play an important role in cell differentiation, as they can regulate the expression of particular genes without affecting the DNA sequence. These changes are therefore reversible, which makes them potential therapeutic targets. Drugs targeting some of these changes are already in clinical use. Several genes known to be involved in DNA methylation, or histone modifications, are affected by somatic mutations in myeloid malignancies [66]. It has even been shown that patients with AML can be clustered into 16 different populations according to their aberrant DNA methylation profiles, most of which correspond to current classification subtypes of AML according to the fusion genes or mutations present [67]. Somatic mutation in epigenetic modifiers are shared among all myeloid malignancies and affect TET2, IDH1/2, DNMT3A, and ASXL1 as well as members of the polycomb repressor complex 2 (PRC2). In MPN they are predominantly found in patients with PMF, or patients who show disease progression to AML; however, their specific role remains unclear, as these mutations are widely detected in different cancers. They may exert a cooperative effect with different combinations of other affected genes to cause a phenotypic readout. Recent evidence of JAK2 involvement in epigenetic regulation underlines the significance of epigenetic mechanisms in disease development [22]. In one recent study, DNA methylation profiling of 29 MPN patients was performed in an attempt to reveal differences at the epigenetic level between the three disease entities [68]. Studies of larger patient cohorts will be necessary to further delineate the methylomes of MPN patients.

\section{Mutations affecting TET2}

The TET proteins (TET1, TET2, and TET3) are enzymes that catalyze the conversion of 5-methylated cytosine into the hydroxymethylated cytosine and require $\mathrm{Fe}(\mathrm{II})$ and $\alpha$ ketoglutarate as cofactors [69]. Deletions of chromosomal region $4 \mathrm{q} 24$ mapping to the TET2 gene are observed in various myeloid malignancies $[45,70]$. Sequence analysis of TET2 revealed that this gene is also commonly affected by point or frameshift mutations, targeting mainly exons 3 (41\%) and $11(29.1 \%)$ [70-73], leading to the loss of its enzymatic function [74].

It appears that each of the TET protein family members has a unique function, as mutations in TETI or TET3 are extremely rare. Haploinsufficiency of TET2 seems to be enough to contribute to the disease phenotype, as in most cases only one allele is affected, although biallelic mutations have been reported. TET2 mutations can arise in both $J A K 2$-V617F-positive and -negative patients, and several studies have shown that the order of acquisition of these two genetic defects is random [70, 75]. Although association of TET2 mutations with disease progression has been observed, no prognostic relevance of these mutations in MPN has been established.

Recent studies have found evidence that the TET2 protein can catalyze stepwise oxidation of 5-methyl-cytosine into not only 5 -hydroxymethyl-cytosine $(5 \mathrm{hmC})$, but also 5-formylcytosine and 5-carboxylcytosine $(5 \mathrm{caC})$ and that the presence of these nucleotides in mouse embryonic stem cells DNA is dependent on the level of TET protein expression [76]. However, $5 \mathrm{hmC}$ can also be deaminated by AID/APOBEC deaminases into 5-hydroxymethyluracil ( $5 \mathrm{hmU})$. The importance of these findings lies in the fact that $5 \mathrm{caC}$ and $5 \mathrm{hmU}$ can be recognized, excised, and replaced with an unmethylated cytosine through the base-excision repair mechanism, in which thymine DNA glycosylase (TDG) plays an important role [77-79]. Therefore, TET2 is a key player in active demethylation of DNA, which has many implications in the role of TET2 haploinsufficiency in development of myeloid malignancies. Studies of TET2 in mouse models provided evidence that TET2 deficiency reduces the levels of $5 \mathrm{hmC}$ in genomic DNA, impairs differentiation of hematopoietic stem cells (HSC), and increases their repopulation capacity in competitive transplant experiments [73, 80-82]. Deletion of Tet 2 causes a CMML-like phenotype in mice after 4-5 months, with evidence of extramedullary hematopoiesis, splenomegaly, and increases in HSC and 
multipotent progenitor populations [73, 80-82]. This latency in disease development suggests that TET2 mutations require additional genetic events to lead to a malignant phenotype.

TET2 mutations are found in $~ 4 \%$ of ET, $9.8-16 \%$ of PV, and $8-14 \%$ of PMF $[71,72]$. A recent study showed, however, that somatic TET2 mutations are present in $5.6 \%$ of elderly individuals with clonal hematopoiesis, who do not have a hematological malignancy [83]. In a 5-year follow-up of seven such patients, one patient acquired a $J A K 2-\mathrm{V} 617 \mathrm{~F}$ mutation and developed ET. Although mutations in several other genes were found to be overlapping with TET2 mutations in patients, further studies will be needed to explain the exact involvement of TET2 in the disease initiation process.

\section{Mutations of $I D H 1 / 2$}

Isocitrate dehydrogenase (IDH) 1 and 2 are $\mathrm{NADP}^{+}$ dependent enzymes, which catalyze the conversion of isocitrate to $\alpha$-ketoglutarate, in cytoplasm and mitochondria, respectively. Somatic mutations affecting $I D H 1$ and $I D H 2$ genes were first described in gliomas and AML [84-86]. Their incidence in MPN is estimated $0.8 \%$ in ET, $1.9 \%$ in PV, $\sim 4.2 \%$ in PMF, and $\sim 21 \%$ of post-MPN AML cases [87, 88] (Fig. 2). It has also been shown that in addition to association with leukemic transformation, $I D H$ mutations predict poor survival in MPN patients [89]. Mutations in IDH1/2 can occur on both JAK2-V617F positive and negative background, suggesting that leukemia can arise from the MPN clone, or as a separate clonal disorder [90]. Co-occurrence with other MPN-specific mutations has been observed.

Mutations in $I D H 1 / 2$ are associated with cytogenetically normal de novo AML, and much effort has been made to better understand their contribution to leukemia initiation [91]. The mutations in $I D H 1$ affect the arginine residue on position 132 in exon 4, and its analogue in $I D H 2$-R172, indicating a gain of function. Mutations in $I D H 2$ at position R140 have also been reported. IDH2 mutations are more common than $I D H I$, and the two are always mutually exclusive [59, 91]. IDH1-R132H has recently been characterized in a knock-in mouse model, in which mice expressing mutant IDH1 show an increase in the early hematopoietic inhibitors, while developing a progressive splenomegaly, and ultimately anemia [92]. Several research groups have demonstrated that mutant IDH converts $\alpha$-ketoglutarate into 2 -hydroxyglutarate $(2 \mathrm{HG})$ in a NADPH-dependent manner, while losing the ability to use isocitrate as a substrate [86, 91, 93]. Accordingly, all AML patients carrying IDHI/2 mutations show elevated $2 \mathrm{HG}$ levels [91]. As TET2 requires $\alpha$-ketoglutarate as a cofactor, mutations in IDH1/2 inhibit TET2 activity, leading to a decrease in hydroxylation of 5-methyl-cytosines and demethylation [94, 95]. Evidence that mutations in IDH1/2 and TET2 rarely co-occur and that patients with these mutations show overlapping hypermethylation signatures [94] indicate that these lesions act through the same mechanism in causing leukemia. Increased 2HG levels can also lead to inhibition of histone demethylases [96], which may be an additional mechanism for leukemogenesis.

\section{Mutations of the DNMT3A gene}

DNMT3A is a DNA methyltransferase responsible for de novo addition of a methyl group to the cytosine within $\mathrm{CpG}$ dinucleotides. It belongs to a methyltransferase family of proteins, together with DNMT3B, which has a similar function, and DNMT1, which is thought to play a role in maintenance of the methylated state. Although mutations in DNMT3A are frequently found across myeloid malignancies, mutations in DNMT3B or DNMT1 have not been reported. DNMT3A mutations were first described in $22 \%$ of AML cases [97]. Subsequently, it was shown that these mutations are an independent prognostic factor of poor survival.

It is unclear if DNMT3A functions as an oncogene or a tumor suppressor. Most of the mutations described affect one amino acid residue (R882) suggesting a gain-of-function mechanism, while the rest of the mutations are mainly frameshifts or premature stop codons scattered throughout the gene, suggesting a loss of function [97-99]. However, in all mutated cases the mutations are heterozygous, implying that the presence of the wild-type allele is necessary and that the mutated protein might act as a dominant negative. This notion is supported by in vitro studies showing decreased catalytic activity of the mutated protein [100].

DNMT3A mutations were reported in $\sim 10 \%$ of MPN patients having higher prevalence in PMF and patients progressing to AML ( 15\%) than ET and PV (3 and $7 \%$, respectively) [98, 99] (Fig. 2). Patients harboring DNMT3A mutations often carry mutations in IDH1/2, TET2, ASXL1 or $J A K 2$. It is unclear how mutations in this gene contribute to disease pathogenesis. A conditional Dnmt3a deletion in the mouse hematopoietic system affects the self-renewing capacity of long-term HSC, causing their expansion while impairing their differentiation without development of a malignant phenotype, as demonstrated by a serial transplantation model [101]. Hypomethylation and up-regulation of genes involved in the pluripotency of HSC in this model suggests that DNMT3A plays an important role in their silencing, thus permitting differentiation [101]. However, effects on gene expression in patients carrying DNMT3A mutations have not been studied. 


\section{Mutations affecting $A S X L 1$}

Additional sex comb like 1 gene (ASXLl) encodes a nuclear polycomb protein that can act both as activator and repressor of transcription through various mechanisms, mainly involving histone modifications [102, 103]. Absence of the homologue of this protein, Asx, in Drosophila prevents deubiquitination of histone $\mathrm{H} 2 \mathrm{~A}$ and repression of HOX genes [104]. Although mutations in ASXL1 have been reported in various myeloid malignancies, Asxll knock-out mice present only mild defects in myelopoiesis, without exhibiting a phenotype related to myeloid malignancies other than splenomegaly [105]. A recent study showed evidence that loss of Asxll enhances the effects of oncogenic NRas-G12D expression in vivo in causing a myeloproliferative disorder phenotype [106]. However, we cannot exclude the possibility that ASXL1 mutations described in myeloid malignancies that lead to truncation of the plant homo domain (PHD) of the ASXL1 protein act as gain-of-function or dominant negative mutations.

Mutations affecting exon 12 of ASXL1 have been described in $7.8 \%$ of 64 MPN cases in one study [107]. Further studies on larger patient cohorts revealed that ASXL1 mutations are more frequent (up to $36 \%$ ) in patients with PMF and patients showing disease progression to secondary myelofibrosis, than in PV or ET [108, 109].

\section{Aberrations of the polycomb repressive complex 2}

Polycomb repressive complex 2 (PRC2) is a protein complex that plays an important role in the regulation of development, cell proliferation, and differentiation through histone modifications that lead to transcriptional repression [110]. The enzymatic core of the PRC2 complex consists of EZH2 (alternatively EZH1), SUZ12, RBAP46/48, and EED. The other members of this complex are AEBP2, JARID2, PHF1, PHF19, and MTF2. EZH1, and EZH2 are methyltransferases that can di- or trimethylate lysine 27 of histone 3 (H2K27me2/3) [111, 112]. Although inactivation of PRC2 complex members leads to reduced levels of $\mathrm{H} 3 \mathrm{~K} 27 \mathrm{me} / 3$, this is not the case for EZH1, which displays lower methyltransferase activity [113]. This may be the reason why $E Z H 2$, but not $E Z H 1$, is commonly affected by somatic mutations in cancer. In myeloid malignancies, it is mainly a target of deletions or truncating loss-of-function mutations [114, 115], although a gain-of-function mutation has been described in B cell-lymphomas [116] and overexpression has been linked to various cancers [117]. In vitro studies have shown that reduced levels of H2K27me3 were also observed after ASXL1 knock-down, and that ASXL1 physically associates with EZH2, indicating that loss of ASXL1 function inhibits recruitment of PRC2 complex to target loci [106].

Somatic mutations in EZH2 are found in $12 \%$ of patients with MPN/MDS [114] and 6-13\% of patients with myelofibrosis, in whom they predict poor survival [118]. Mutations affecting SUZ12 are found in $1.4 \%, E E D$ in $1 \%$ and JARID2 in $2 \%$ of MDS/MPN cases [119]. Focal homozygous deletions affecting single genes JARID2 and $A E B P 2$ have been described in patients with PV and post-MDS AML, respectively [120]. Inactivation of members of PRC2 complex is often achieved through homo- or hemizygous deletions, as well as acquired losses of heterozygosity. Overall, they seem to be more frequent in patients that show disease progression towards leukemia. However, further functional studies will be necessary to delineate the mechanism by which inactivation of PRC2 complex leads to myeloid malignancies, and their relation to other gene mutations.

\section{The role of cytogenetic aberrations in MPN}

Diagnostic work-up of patients with myeloid malignancies often includes classical cytogenetic karyotype analysis, which enables detection of translocations and large-scale chromosomal aberrations. Many of the aberrations detected are used for characterization and classification of hematological malignancies, such as the most famous case of the $B C R-A B L$ fusion ("Philadelphia chromosome") in CML. Development of microarray technology enabled analysis of copy number changes, as well as the detection of acquired losses of heterozygosity across the entire genome, at resolutions unreached by classical cytogenetic analysis. The importance of uniparental disomies in cancer development is that these aberrations lead to homozygosity through mitotic recombination of non-sister chromatids, whereby mutated tumor suppressors and oncogenes can be amplified, conferring an additional clonal advantage to affected cells [121]. Microarray technology was used to detect recurrent cytogenetic aberrations, which may point to novel genes involved in disease pathogenesis [45, 122, 123]. The largest cohort study of 408 MPN patients, using SNP arrays that provide 1.8 million data points per genome, revealed that $37.5 \%$ of MPN patients show no detectable cytogenetic aberration, while in $62.5 \%$ at least one aberration was present [45]. Karyotype complexity did not differ between patients with ET, PV, or PMF. However, higher cytogenetic complexity was observed in patients showing disease progression to secondary myelofibrosis or AML. Several cytogenetic aberrations were recurrent in the MPN patient cohort, such as 9p UPD, 1p UPD, del20q, del13q, 14q UPD, 1q gain, trisomy 8, del4q, and 7q UPD [45] 
Fig. 3 Frequencies of recurrent cytogenetic aberrations in patients with myeloproliferative neoplasms during chronic phase (a) and acute leukemic phase (b) of the disease. $M P N$ myeloproliferative neoplasm, $A M L$ acute myeloid leukemia

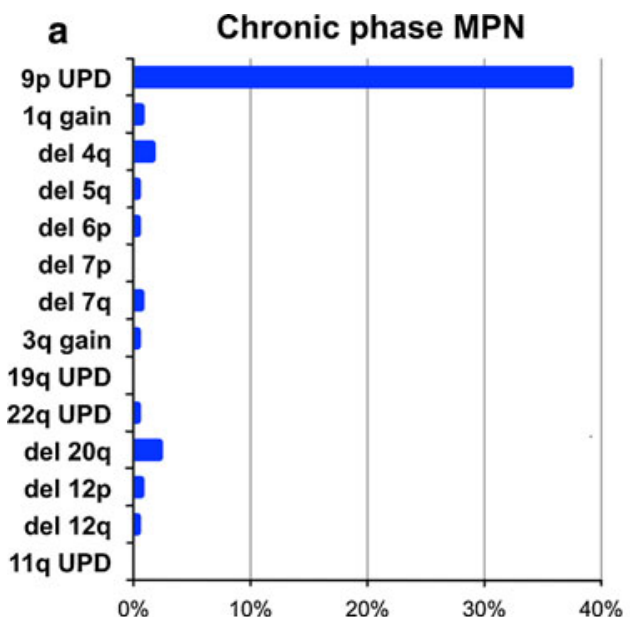

(Fig. 3). The most frequent cytogenetic aberration in MPN patients was UPD of chromosome 9p. All samples with 9p UPD and most samples with 1p UPD carried mutations of $J A K 2$ and MPL, respectively [45]. In PV $68 \%$ of JAK2V617F positive patients also had a UPD of chromosome 9p [45], while patients with ET exhibited low frequency of this aberration [124]. Excluding the 9pUPD, MPN patients had the same frequency of cytogenetic aberrations regardless of their $J A K 2$ mutational status. The high resolution of the copy number analysis allowed the mapping of common affected regions to single genes in this study, including IKZF1, CUX1, TET2, FOXP1, ETV6, and RUNX1 [45]. Deletions targeting TET2, FOXP1, ETV6, as well as del13q and del20q, were found in similar frequencies in both the chronic and leukemic phases of the disease, suggesting a more universal role in its pathogenesis. ETV6 has been previously implicated in different hematological cancers as a fusion partner of $A B L 1, R U N X 1$ and other genes, due to translocations involving chromosome 12 [125, 126]. Deletions of FOXPI have previously been reported in cancer, and it is considered to be a putative tumor suppressor [127]. Since these proteins are transcription factors, it is uncertain which property of HSC is affected by their decreased dosage. Although del20q and del13q are frequent chromosomal aberrations found in various myeloid malignancies, the common deleted region contains numerous genes and the targets of these aberrations remain unknown [128]. Deletions of $7 \mathrm{p}$ targeting $I K Z F 1$, and $7 \mathrm{q}$ targeting $C U X 1$ were found to be associated with disease progression and are discussed in the following section.

\section{Genetic aberrations associated with disease progression}

Myeloproliferative neoplasms can progress to secondary myelofibrosis (also called accelerated phase in ET and PV) or AML. Many MPN patients develop anemia and progressive accumulation of blasts in peripheral blood or bone marrow, which are also characteristics of accelerated phase of the disease in all three disease entities. The current criteria for diagnosis of post-MPN AML is the presence of $20 \%$ or more blasts in the peripheral blood and/or bone marrow [1], and the rate of leukemic transformation in MPN is $7 \%$ [129]. Patients with secondary AML have poor prognosis, with an adverse outcome within a few months after leukemic transformation [59]. The genetic basis of transformation to leukemia remains poorly understood. Recent studies on limited patient cohorts have shown that different somatic cytogenetic lesions and mutations may lead to leukemia development.

Mutations affecting tumor suppressor p53 (TP53) were found to be associated with post-MPN AML comparing both with the chronic phase and de novo AML. They are detected in $27.3 \%$ of post-MPN AML, $1.6 \%$ of chronic phase MPN (Fig. 2), and $4.27 \%$ of de novo AML patients $[59,130]$. While mutations affecting chronic phase patients were monoallelic, they were usually biallelic in secondary AML and associated with 17p UPD or deletions. Interestingly, the $1 \mathrm{q}$ locus containing the gene encoding MDM4, a known inhibitor of p53 was repeatedly found to be amplified in post-MPN AML [45, 59]. As previously reported in solid tumors [131], gains of 1q were mutually exclusive with p53 mutations, indicating that these two genetic lesions affect the same pathway, which then seems to contribute to $45.5 \%$ of the post-MPN AML cases [130]. The significance of this pathway in leukemic transformation is further supported by the finding that TP53 mutations are the only independent prognostic factor of poor survival in secondary AML [59]. Considering the low frequency of mutations affecting TP53 in chronic phase MPN patients, this mutation can be used as a predictor of leukemic transformation in MPN patients. The extent to which therapy administered during the chronic phase of the 
disease influences inactivation of p53 pathway leading to transformation is unclear [132].

IDHI/2 mutations are present in $\sim 12 \%$ of patients with leukemic transformation, and their role has been described in a previous section of this review, as well as mutations affecting TET2 which are found in $28.3 \%$ of post-MPN AML patients [65]. The frequency of $I D H 1 / 2$ mutations does not differ between de novo and secondary AML patients [59]. Large-scale changes in the methylation patterns that enable classification of AML indicate the significance of epigenetic regulators in disease pathogenesis [67]. Mutations in RUNX1, which encodes a transcription factor involved in hematopoiesis, have been reported in AML, post-MDS AML, and post-MPN AML [59, 133136]. Regarding the cytogenetic aberrations linked to the disease progression, the first observation was that patients with ET and PV who carry a 9p UPD, and consequently a higher $J A K 2$-V617F mutational burden, show higher incidence of progression to secondary myelofibrosis. In general, patients with post-MPN AML have more complex karyotypes compared with chronic phase, with complex karyotype being present in $\sim 45 \%$ of patients with postMPN and post-MDS AML [59]. Other cytogenetic lesions associated with post-MPN AML include del5q, del6p, del7p, del7q, gain3q, 19q UPD, and 22q UPD (Fig. 3). Monosomy of chromosome 7 is one of the most common cytogenetic aberrations in myeloid malignancies, often linked to poor prognosis. Deletions of $7 \mathrm{p}$ were found in six of 23 post-MPN AML patients and target transcription factor IKAROS encoded by IKZFI gene [137]. This genetic aberration was rare in the chronic phase $(<1 \%$ of cases) and was described as a late genetic event in the evolution of the leukemic clone. In vitro studies showed that knock-down of Ikaros causes cytokine hypersensitivity in hematopoietic progenitors [137]. Overexpression of a dominant negative isoform of this protein was linked to activation of JAK-STAT signaling pathway [138]. This transcription factor is known to be involved in regulation of differentiation of lymphoid cells, and is frequently affected in ALL, indicating its general role in leukemogenesis. Deletions of 7q target the CUX1 gene. CUX1 is a transcription factor involved in regulation of cell cycle and hematopoiesis [139, 140]. Although the exact function of CUX1 in leukemic transformation remains to be described, a recent study reported that CUX1 deficiency negatively regulates the expression of members of the ATM/p53 pathway [141]. Deletions of chromosome 17q11.2 targeting NFI are also found in patients showing disease progression. NF1 encodes neurofibromin 1, which negatively regulates RAS and is involved in granulocyte-macrophage colony-stimulating factor signaling [142]. Biallelic mutations of NF1 in MPN including frameshift mutations and deletions of the second allele have been reported, and there is evidence that loss of NFI leads to development of a progressive myeloproliferative disorder [143]. Mutations in $N R A S$ affecting the same pathway have also been described in post-MPN AML [58].

There are two hypotheses on the emergence of the leukemic clone in MPN patients (Fig. 1). The first argues that the MPN clone acquires additional genetic lesions that lead to impairment of differentiation and accumulation of blasts, while the second postulates that AML can arise as a separate disease in the same patient from an independent clone. The second hypothesis is supported by recent evidence that the leukemic blasts in MPN patients are often lacking the mutations found in the MPN clone [58, 144]. In line with this finding, it would be expected that secondary AML share the genetic features with AML arising de novo; however, recent finding suggest otherwise. Mutations commonly detected in de novo AML such as FLT3 and $N P M 1$, occur at much lower frequencies in secondary AML. Several gene mutations such as TET2, RUNX1, $I D H 1 / 2$, and NRAS, and deletions of IKZFI and NFI were found in similar frequencies between post-MPN and de novo AML [59, 108], indicating that these genes are involved in the general leukemogenesis pathway, which is not dependent on the disease etiology. In contrast, mutations in TP53, gains of $1 \mathrm{q}$ and deletions of $7 \mathrm{q}$ targeting CUXI seem to be specific for secondary AML. It is important to stress that no somatic genetic lesions are detectable in approximately one-third of post-MPN AML patients. Application of next generation sequencing technologies in the analysis of their genomes will help elucidate the underlying cause of leukemic transformation in these patients.

\section{Familial myeloproliferative neoplasms}

Despite many somatic mutations and chromosomal aberrations described in MPN, there are several lines of evidence that germline genetic factors also contribute to MPN pathogenesis and disease progression. Familial clustering of MPN has been reported in various studies [145-150]. In general, 5-10\% of MPNs account for familial cases [150] and it has been shown that relatives of MPN patients are at higher risk of developing the disease [151]. The causative germline mutations in many of the familial cases are unknown [152]. Germline mutations in $M P L$, and recently in $J A K 2$, have been reported in several familial cases of thrombocytosis [31, 153-155]. Another interesting finding was that the GGCC (also known as 46/1) haplotype in the $J A K 2$ locus predisposes to JAK2-V617F positive MPN [156]. Further studies demonstrated that the same haplotype represents a susceptibility factor for ET and PMF regardless of the JAK2 status [157, 158]. However, the 
frequency of the GGCC haplotype was found to be similar for the familial and sporadic MPN cases, and thus, it cannot explain familial clustering of MPN [159]. With respect to disease progression, a coding polymorphism in the codon 751 of XPD gene was shown to be associated with leukemic transformation as well as development of non-myeloid malignancies in patients with PV and ET [160]. Furthermore, germline mutations in regions of somatic loss of heterozygosity may exert a phenotypic effect in blood cells and modulate the MPN phenotype [161].

\section{Conclusion}

The diversity of somatic lesions in patients with the diagnosis of MPN indicates that the clonal evolution of MPN stem cells involves a number of cellular pathways. In general the mutations identified in MPN either target cytokine receptor signaling or involve aberrant gene expression via epigenetic regulation, reduced function of transcription factors or via aberrant splicing. In addition, the leukemic transformation process of MPN targets the DNA damage response pathway. Patients often carry a number of somatic lesions that are acquired in sequential order within a single clone. However, patients with biclonal hematopoiesis have been identified with two clones evolving side by side, each having a different potential to influence the hematological phenotype. The genetic complexity of MPN will further increase with new knowledge uncovered by high-throughput sequencing. It is clear by now that each MPN patient will represent a unique entity based on the somatic genetic profile of the MPN clone. Highly individualized diagnostic and therapeutic approaches will be required for successful clinical management of this phenotypically and genetically diverse disease group.

Acknowledgments This study was supported by the Austrian Science Fund (P23257-B12) and the MPN Research Foundation.

Conflict of interest None.

\section{References}

1. Vardiman JW, Thiele J, Arber DA, Brunning RD, Borowitz MJ, Porwit A, et al. The 2008 revision of the World Health Organization (WHO) classification of myeloid neoplasms and acute leukemia: rationale and important changes. Blood. 2009;114(5):937-51.

2. Baxter EJ, Scott LM, Campbell PJ, East C, Fourouclas N, Swanton S, et al. Acquired mutation of the tyrosine kinase JAK2 in human myeloproliferative disorders. Lancet. 2005;365(9464): 1054-61.

3. James C, Ugo V, Le Couedic JP, Staerk J, Delhommeau F, Lacout $\mathrm{C}$, et al. A unique clonal JAK2 mutation leading to constitutive signalling causes polycythaemia vera. Nature. 2005; 434(7037):1144-8.

4. Kralovics R, Passamonti F, Buser AS, Teo SS, Tiedt R, Passweg JR, et al. A gain-of-function mutation of JAK2 in myeloproliferative disorders. N Engl J Med. 2005;352(17):1779-90.

5. Levine RL, Wadleigh M, Cools J, Ebert BL, Wernig G, Huntly $\mathrm{BJ}$, et al. Activating mutation in the tyrosine kinase JAK2 in polycythemia vera, essential thrombocythemia, and myeloid metaplasia with myelofibrosis. Cancer Cell. 2005;7(4):387-97.

6. Pietra D, Li S, Brisci A, Passamonti F, Rumi E, Theocharides A, et al. Somatic mutations of JAK2 exon 12 in patients with JAK2 (V617F)-negative myeloproliferative disorders. Blood. 2008;111(3):1686-9.

7. Scott LM, Tong W, Levine RL, Scott MA, Beer PA, Stratton $\mathrm{MR}$, et al. JAK2 exon 12 mutations in polycythemia vera and idiopathic erythrocytosis. N Engl J Med. 2007;356(5):459-68.

8. Vainchenker W, Delhommeau F, Constantinescu SN, Bernard OA. New mutations and pathogenesis of myeloproliferative neoplasms. Blood. 2011;118(7):1723-35.

9. Tefferi A. Novel mutations and their functional and clinical relevance in myeloproliferative neoplasms: JAK2, MPL, TET2, ASXL1, CBL, IDH and IKZF1. Leukemia. 2010;24(6):1128-38.

10. Jatiani SS, Baker SJ, Silverman LR, Reddy EP. Jak/STAT pathways in cytokine signaling and myeloproliferative disorders: approaches for targeted therapies. Genes Cancer. 2010; 1(10):979-93.

11. Saharinen P, Silvennoinen O. The pseudokinase domain is required for suppression of basal activity of Jak2 and Jak3 tyrosine kinases and for cytokine-inducible activation of signal transduction. J Biol Chem. 2002;277(49):47954-63.

12. Baker SJ, Rane SG, Reddy EP. Hematopoietic cytokine receptor signaling. Oncogene. 2007;26(47):6724-37.

13. Kralovics R, Guan Y, Prchal JT. Acquired uniparental disomy of chromosome $9 p$ is a frequent stem cell defect in polycythemia vera. Exp Hematol. 2002;30(3):229-36.

14. Funakoshi-Tago M, Tago K, Abe M, Sonoda Y, Kasahara T. STAT5 activation is critical for the transformation mediated by myeloproliferative disorder-associated JAK2 V617F mutant. J Biol Chem. 2010;285(8):5296-307.

15. Lu X, Levine R, Tong W, Wernig G, Pikman Y, Zarnegar S, et al. Expression of a homodimeric type I cytokine receptor is required for JAK2V617F-mediated transformation. Proc Natl Acad Sci USA. 2005;102(52):18962-7.

16. Akada H, Yan D, Zou H, Fiering S, Hutchison RE, Mohi MG. Conditional expression of heterozygous or homozygous Jak2V617F from its endogenous promoter induces a polycythemia vera-like disease. Blood. 2010;115(17):3589-97.

17. Wernig G, Mercher T, Okabe R, Levine RL, Lee BH, Gilliland DG. Expression of Jak2V617F causes a polycythemia vera-like disease with associated myelofibrosis in a murine bone marrow transplant model. Blood. 2006;107(11):4274-81.

18. Shide K, Shimoda HK, Kumano T, Karube K, Kameda T, Takenaka K, et al. Development of ET, primary myelofibrosis and PV in mice expressing JAK2 V617F. Leukemia. 2008; 22(1):87-95.

19. Tiedt R, Hao-Shen H, Sobas MA, Looser R, Dirnhofer S, Schwaller J, et al. Ratio of mutant JAK2-V617F to wild-type Jak2 determines the MPD phenotypes in transgenic mice. Blood. 2008;111(8):3931-40.

20. Lacout C, Pisani DF, Tulliez M, Gachelin FM, Vainchenker W, Villeval JL. JAK2V617F expression in murine hematopoietic cells leads to MPD mimicking human PV with secondary myelofibrosis. Blood. 2006;108(5):1652-60.

21. Xing S, Wanting TH, Zhao W, Ma J, Wang S, Xu X, et al. Transgenic expression of JAK2V617F causes myeloproliferative disorders in mice. Blood. 2008;111(10):5109-17. 
22. Dawson MA, Bannister AJ, Gottgens B, Foster SD, Bartke T, Green AR, et al. JAK2 phosphorylates histone H3Y41 and excludes HP1alpha from chromatin. Nature. 2009;461(7265): 819-22.

23. Panteleeva I, Boutillier S, See V, Spiller DG, Rouaux C, Almouzni G, et al. HP1alpha guides neuronal fate by timing E2F-targeted genes silencing during terminal differentiation. EMBO J. 2007;26(15):3616-28.

24. Luijsterburg MS, Dinant C, Lans H, Stap J, Wiernasz E, Lagerwerf S, et al. Heterochromatin protein 1 is recruited to various types of DNA damage. J Cell Biol. 2009;185(4):577-86.

25. Liu F, Zhao X, Perna F, Wang L, Koppikar P, Abdel-Wahab O, et al. JAK2V617F-mediated phosphorylation of PRMT5 downregulates its methyltransferase activity and promotes myeloproliferation. Cancer Cell. 2011;19(2):283-94.

26. Pikman Y, Lee BH, Mercher T, McDowell E, Ebert BL, Gozo $\mathrm{M}$, et al. MPLW515L is a novel somatic activating mutation in myelofibrosis with myeloid metaplasia. PLoS Med. 2006;3(7): e270.

27. Staerk J, Lacout C, Sato T, Smith SO, Vainchenker W, Constantinescu SN. An amphipathic motif at the transmembrane-cytoplasmic junction prevents autonomous activation of the thrombopoietin receptor. Blood. 2006;107(5):1864-71.

28. Pardanani AD, Levine RL, Lasho T, Pikman Y, Mesa RA, Wadleigh M, et al. MPL515 mutations in myeloproliferative and other myeloid disorders: a study of 1182 patients. Blood. 2006;108(10):3472-6.

29. Beer PA, Campbell PJ, Scott LM, Bench AJ, Erber WN, Bareford D, et al. MPL mutations in myeloproliferative disorders: analysis of the PT-1 cohort. Blood. 2008;112(1):141-9.

30. Schnittger S, Bacher U, Haferlach C, Beelen D, Bojko P, Burkle $\mathrm{D}$, et al. Characterization of 35 new cases with four different MPLW515 mutations and essential thrombocytosis or primary myelofibrosis. Haematologica. 2009;94(1):141-4.

31. Ding J, Komatsu H, Wakita A, Kato-Uranishi M, Ito M, Satoh A, et al. Familial essential thrombocythemia associated with a dominant-positive activating mutation of the c-MPL gene, which encodes for the receptor for thrombopoietin. Blood. 2004;103(11):4198-200.

32. Pietra D, Brisci A, Rumi E, Boggi S, Elena C, Pietrelli A, et al. Deep sequencing reveals double mutations in cis of MPL exon 10 in myeloproliferative neoplasms. Haematologica. 2011;96(4):607-11.

33. Pardanani A, Lasho TL, Finke C, Mesa RA, Hogan WJ, Ketterling RP, et al. Extending Jak2V617F and MplW515 mutation analysis to single hematopoietic colonies and $\mathrm{B}$ and $\mathrm{T}$ lymphocytes. Stem Cells. 2007;25(9):2358-62.

34. Szpurka H, Gondek LP, Mohan SR, Hsi ED, Theil KS, Maciejewski JP. UPD1p indicates the presence of MPL W515L mutation in RARS-T, a mechanism analogous to UPD9p and JAK2 V617F mutation. Leukemia. 2009;23(3):610-4.

35. Buxhofer-Ausch V, Gisslinger H, Berg T, Gisslinger B, Kralovics R. Acquired resistance to interferon alpha therapy associated with homozygous MPL-W515L mutation and chromosome 20q deletion in primary myelofibrosis. Eur J Haematol. 2009;82(2):161-3.

36. Boyd EM, Bench AJ, Goday-Fernandez A, Anand S, Vaghela $\mathrm{KJ}$, Beer $\mathrm{P}$, et al. Clinical utility of routine MPL exon 10 analysis in the diagnosis of essential thrombocythaemia and primary myelofibrosis. Br J Haematol. 2010;149(2):250-7.

37. Oh ST, Simonds EF, Jones C, Hale MB, Goltsev Y, Gibbs KD $\mathrm{Jr}$, et al. Novel mutations in the inhibitory adaptor protein LNK drive JAK-STAT signaling in patients with myeloproliferative neoplasms. Blood. 2010;116(6):988-92.

38. Lasho TL, Pardanani A, Tefferi A. LNK mutations in JAK2 mutation-negative erythrocytosis. N Engl J Med. 2010;363(12): $1189-90$.
39. Tong W, Lodish HF. Lnk inhibits Tpo-mpl signaling and Tpomediated megakaryocytopoiesis. J Exp Med. 2004;200(5): 569-80.

40. Tong W, Zhang J, Lodish HF. Lnk inhibits erythropoiesis and Epo-dependent JAK2 activation and downstream signaling pathways. Blood. 2005;105(12):4604-12.

41. Gery S, Cao Q, Gueller S, Xing H, Tefferi A, Koeffler HP. Lnk inhibits myeloproliferative disorder-associated JAK2 mutant, JAK2V617F. J Leukoc Biol. 2009;85(6):957-65.

42. Gery S, Gueller S, Chumakova K, Kawamata N, Liu L, Koeffler HP. Adaptor protein Lnk negatively regulates the mutant MPL, MPLW515L associated with myeloproliferative disorders. Blood. 2007;110(9):3360-4.

43. Velazquez L, Cheng AM, Fleming HE, Furlonger C, Vesely S, Bernstein A, et al. Cytokine signaling and hematopoietic homeostasis are disrupted in Lnk-deficient mice. J Exp Med. 2002;195(12):1599-611.

44. Pardanani A, Lasho T, Finke C, Oh ST, Gotlib J, Tefferi A. LNK mutation studies in blast-phase myeloproliferative neoplasms, and in chronic-phase disease with TET2, IDH, JAK2 or MPL mutations. Leukemia. 2010;24(10):1713-8.

45. Klampfl T, Harutyunyan A, Berg T, Gisslinger B, Schalling M, Bagienski $\mathrm{K}$, et al. Genome integrity of myeloproliferative neoplasms in chronic phase and during disease progression. Blood. 2011;118(1):167-76.

46. Sargin B, Choudhary C, Crosetto N, Schmidt MH, Grundler R, Rensinghoff $M$, et al. Flt3-dependent transformation by inactivating $\mathrm{c}-\mathrm{Cbl}$ mutations in AML. Blood. 2007;110(3): 1004-12.

47. Caligiuri MA, Briesewitz R, Yu J, Wang L, Wei M, Arnoczky $\mathrm{KJ}$, et al. Novel c-CBL and CBL-b ubiquitin ligase mutations in human acute myeloid leukemia. Blood. 2007;110(3):1022-4.

48. Abbas S, Rotmans G, Lowenberg B, Valk PJ. Exon 8 splice site mutations in the gene encoding the E3-ligase CBL are associated with core binding factor acute myeloid leukemias. Haematologica. 2008;93(10):1595-7.

49. Dunbar AJ, Gondek LP, O'Keefe CL, Makishima H, Rataul MS, Szpurka H, et al. 250K single nucleotide polymorphism array karyotyping identifies acquired uniparental disomy and homozygous mutations, including novel missense substitutions of c-Cbl, in myeloid malignancies. Cancer Res. 2008;68(24): $10349-57$.

50. Grand FH, Hidalgo-Curtis CE, Ernst T, Zoi K, Zoi C, McGuire $\mathrm{C}$, et al. Frequent CBL mutations associated with $11 \mathrm{q}$ acquired uniparental disomy in myeloproliferative neoplasms. Blood. 2009;113(24):6182-92.

51. Sanada M, Suzuki T, Shih LY, Otsu M, Kato M, Yamazaki S, et al. Gain-of-function of mutated C-CBL tumour suppressor in myeloid neoplasms. Nature. 2009;460(7257):904-8.

52. Schmidt MH, Dikic I. The Cbl interactome and its functions. Nat Rev Mol Cell Biol. 2005;6(12):907-18.

53. Saur SJ, Sangkhae V, Geddis AE, Kaushansky K, Hitchcock IS. Ubiquitination and degradation of the thrombopoietin receptor c-Mpl. Blood. 2010;115(6):1254-63.

54. Rathinam C, Thien CB, Langdon WY, Gu H, Flavell RA. The E3 ubiquitin ligase c-Cbl restricts development and functions of hematopoietic stem cells. Genes Dev. 2008;22(8):992-7.

55. Naramura M, Nandwani N, Gu H, Band V, Band H. Rapidly fatal myeloproliferative disorders in mice with deletion of Casitas B-cell lymphoma (Cbl) and Cbl-b in hematopoietic stem cells. Proc Natl Acad Sci USA. 2010;107(37):16274-9.

56. Reindl C, Quentmeier H, Petropoulos K, Greif PA, Benthaus T, Argiropoulos B, et al. CBL exon 8/9 mutants activate the FLT3 pathway and cluster in core binding factor/11q deletion acute myeloid leukemia/myelodysplastic syndrome subtypes. Clin Cancer Res. 2009;15(7):2238-47. 
57. Bandi SR, Brandts C, Rensinghoff M, Grundler R, Tickenbrock L, Kohler G, et al. E3 ligase-defective Cbl mutants lead to a generalized mastocytosis and myeloproliferative disease. Blood. 2009; 114(19):4197-208.

58. Beer PA, Delhommeau F, LeCouedic JP, Dawson MA, Chen E, Bareford D, et al. Two routes to leukemic transformation after a JAK2 mutation-positive myeloproliferative neoplasm. Blood. 2010;115(14):2891-900.

59. Milosevic JD, Puda A, Malcovati L, Berg T, Hofbauer M, Stukalov A, et al. Clinical significance of genetic aberrations in secondary acute myeloid leukemia. Am J Hematol. 2012; 87(11):1010-6.

60. Yoshida K, Sanada M, Shiraishi Y, Nowak D, Nagata Y, Yamamoto R, et al. Frequent pathway mutations of splicing machinery in myelodysplasia. Nature. 2011;478(7367):64-9.

61. Lasho TL, Finke CM, Hanson CA, Jimma T, Knudson RA, Ketterling RP, et al. SF3B1 mutations in primary myelofibrosis: clinical, histopathology and genetic correlates among 155 patients. Leukemia. 2012;26(5):1135-7.

62. Papaemmanuil E, Cazzola M, Boultwood J, Malcovati L, Vyas $\mathrm{P}$, Bowen D, et al. Somatic SF3B1 mutation in myelodysplasia with ring sideroblasts. N Engl J Med. 2011;365(15):1384-95.

63. Visconte V, Makishima H, Jankowska A, Szpurka H, Traina F, Jerez A, et al. SF3B1, a splicing factor is frequently mutated in refractory anemia with ring sideroblasts. Leukemia. 2012;26(3): $542-5$.

64. Lasho TL, Jimma T, Finke CM, Patnaik M, Hanson CA, Ketterling RP, et al. SRSF2 mutations in primary myelofibrosis: significant clustering with IDH mutations and independent association with inferior overall and leukemia-free survival. Blood. 2012;120(20):4168-71.

65. Zhang SJ, Rampal R, Manshouri T, Patel J, Mensah N, Kayserian A, et al. Genetic analysis of patients with leukemic transformation of myeloproliferative neoplasms shows recurrent SRSF2 mutations that are associated with adverse outcome. Blood. 2012;119(19):4480-5.

66. Shih AH, Abdel-Wahab O, Patel JP, Levine RL. The role of mutations in epigenetic regulators in myeloid malignancies. Nat Rev Cancer. 2012;12(9):599-612.

67. Figueroa ME, Lugthart S, Li Y, Erpelinck-Verschueren C, Deng $\mathrm{X}$, Christos PJ, et al. DNA methylation signatures identify biologically distinct subtypes in acute myeloid leukemia. Cancer Cell. 2010;17(1):13-27.

68. Nischal S, Bhattacharyya S, Christopeit M, Yu Y, Zhou L, Bhagat $\mathrm{T}$, et al. Methylome profiling reveals distinct alterations in phenotypic and mutational subgroups of myeloproliferative neoplasms. Cancer Res. 2012.

69. Tahiliani M, Koh KP, Shen Y, Pastor WA, Bandukwala H, Brudno Y, et al. Conversion of 5-methylcytosine to 5-hydroxymethylcytosine in mammalian DNA by MLL partner TET1. Science. 2009;324(5929):930-5.

70. Delhommeau F, Dupont S, Della Valle V, James C, Trannoy S, Masse A, et al. Mutation in TET2 in myeloid cancers. N Engl J Med. 2009;360(22):2289-301.

71. Tefferi A, Pardanani A, Lim KH, Abdel-Wahab O, Lasho TL, Patel J, et al. TET2 mutations and their clinical correlates in polycythemia vera, essential thrombocythemia and myelofibrosis. Leukemia. 2009;23(5):905-11.

72. Abdel-Wahab O, Mullally A, Hedvat C, Garcia-Manero G, Patel $\mathrm{J}$, Wadleigh M, et al. Genetic characterization of TET1, TET2, and TET3 alterations in myeloid malignancies. Blood. 2009; 114(1):144-7.

73. Moran-Crusio K, Reavie L, Shih A, Abdel-Wahab O, NdiayeLobry D, Lobry C, et al. Tet2 loss leads to increased hematopoietic stem cell self-renewal and myeloid transformation. Cancer Cell. 2011;20(1):11-24.
74. Ko M, Huang Y, Jankowska AM, Pape UJ, Tahiliani M, Bandukwala HS, et al. Impaired hydroxylation of 5-methylcytosine in myeloid cancers with mutant TET2. Nature. 2010; 468(7325):839-43.

75. Swierczek SI, Yoon D, Bellanne-Chantelot C, Kim SJ, SaintMartin C, Delhommeau F, et al. Extent of hematopoietic involvement by TET2 mutations in JAK2V(6)(1)(7)F polycythemia vera. Haematologica. 2011;96(5):775-8.

76. Ito S, Shen L, Dai Q, Wu SC, Collins LB, Swenberg JA, et al. Tet proteins can convert 5-methylcytosine to 5-formylcytosine and 5-carboxylcytosine. Science. 2011;333(6047):1300-3.

77. Guo JU, Su Y, Zhong C, Ming GL, Song H. Hydroxylation of 5-methylcytosine by TET1 promotes active DNA demethylation in the adult brain. Cell. 2011;145(3):423-34.

78. He YF, Li BZ, Li Z, Liu P, Wang Y, Tang Q, et al. Tet-mediated formation of 5-carboxylcytosine and its excision by TDG in mammalian DNA. Science. 2011;333(6047):1303-7.

79. Cortellino S, Xu J, Sannai M, Moore R, Caretti E, Cigliano A, et al. Thymine DNA glycosylase is essential for active DNA demethylation by linked deamination-base excision repair. Cell. 2011;146(1):67-79.

80. Ko M, Bandukwala HS, An J, Lamperti ED, Thompson EC, Hastie R, et al. Ten-Eleven-Translocation 2 (TET2) negatively regulates homeostasis and differentiation of hematopoietic stem cells in mice. Proc Natl Acad Sci USA. 2011;108(35):14566-71.

81. Quivoron C, Couronne L, Della Valle V, Lopez CK, Plo I, Wagner-Ballon $\mathrm{O}$, et al. TET2 inactivation results in pleiotropic hematopoietic abnormalities in mouse and is a recurrent event during human lymphomagenesis. Cancer Cell. 2011;20(1): 25-38.

82. Li Z, Cai X, Cai CL, Wang J, Zhang W, Petersen BE, et al. Deletion of Tet 2 in mice leads to dysregulated hematopoietic stem cells and subsequent development of myeloid malignancies. Blood. 2011;118(17):4509-18.

83. Busque L, Patel JP, Figueroa ME, Vasanthakumar A, Provost S, Hamilou Z, et al. Recurrent somatic TET2 mutations in normal elderly individuals with clonal hematopoiesis. Nat Genet. 2012;44(11):1179-81.

84. Parsons DW, Jones S, Zhang X, Lin JC, Leary RJ, Angenendt P, et al. An integrated genomic analysis of human glioblastoma multiforme. Science. 2008;321(5897):1807-12.

85. Mardis ER, Ding L, Dooling DJ, Larson DE, McLellan MD, Chen $\mathrm{K}$, et al. Recurring mutations found by sequencing an acute myeloid leukemia genome. N Engl J Med. 2009; 361(11):1058-66.

86. Yan H, Parsons DW, Jin G, McLendon R, Rasheed BA, Yuan $\mathrm{W}$, et al. IDH1 and IDH2 mutations in gliomas. N Engl J Med. 2009;360(8):765-73.

87. Pardanani A, Lasho TL, Finke CM, Mai M, McClure RF, Tefferi A. IDH1 and IDH2 mutation analysis in chronic- and blast-phase myeloproliferative neoplasms. Leukemia. 2010;24(6):1146-51.

88. Tefferi A, Lasho TL, Abdel-Wahab O, Guglielmelli P, Patel J, Caramazza D, et al. IDH1 and IDH2 mutation studies in 1473 patients with chronic-, fibrotic- or blast-phase essential thrombocythemia, polycythemia vera or myelofibrosis. Leukemia. 2010;24(7):1302-9.

89. Tefferi A, Jimma T, Sulai NH, Lasho TL, Finke CM, Knudson RA, et al. IDH mutations in primary myelofibrosis predict leukemic transformation and shortened survival: clinical evidence for leukemogenic collaboration with JAK2V617F. Leukemia. 2012;26(3):475-80.

90. Green A, Beer P. Somatic mutations of IDH1 and IDH2 in the leukemic transformation of myeloproliferative neoplasms. N Engl J Med. 2010;362(4):369-70.

91. Ward PS, Patel J, Wise DR, Abdel-Wahab O, Bennett BD, Coller HA, et al. The common feature of leukemia-associated 
IDH1 and IDH2 mutations is a neomorphic enzyme activity converting alpha-ketoglutarate to 2-hydroxyglutarate. Cancer Cell. 2010;17(3):225-34.

92. Sasaki M, Knobbe CB, Munger JC, Lind EF, Brenner D, Brustle A, et al. IDH1(R132H) mutation increases murine haematopoietic progenitors and alters epigenetics. Nature. 2012; 488(7413):656-9.

93. Dang L, White DW, Gross S, Bennett BD, Bittinger MA, Driggers EM, et al. Cancer-associated IDH1 mutations produce 2-hydroxyglutarate. Nature. 2009;462(7274):739-44.

94. Figueroa ME, Abdel-Wahab O, Lu C, Ward PS, Patel J, Shih A, et al. Leukemic IDH1 and IDH2 mutations result in a hypermethylation phenotype, disrupt TET2 function, and impair hematopoietic differentiation. Cancer Cell. 2010;18(6):553-67.

95. Xu W, Yang H, Liu Y, Yang Y, Wang P, Kim SH, et al. Oncometabolite 2-hydroxyglutarate is a competitive inhibitor of alpha-ketoglutarate-dependent dioxygenases. Cancer Cell. 2011;19(1):17-30.

96. Chowdhury R, Yeoh KK, Tian YM, Hillringhaus L, Bagg EA, Rose NR, et al. The oncometabolite 2-hydroxyglutarate inhibits histone lysine demethylases. EMBO Rep. 2011;12(5):463-9.

97. Ley TJ, Ding L, Walter MJ, McLellan MD, Lamprecht T, Larson DE, et al. DNMT3A mutations in acute myeloid leukemia. N Engl J Med. 2010;363(25):2424-33.

98. Stegelmann F, Bullinger L, Schlenk RF, Paschka P, Griesshammer M, Blersch C, et al. DNMT3A mutations in myeloproliferative neoplasms. Leukemia. 2011;25(7):1217-9.

99. Abdel-Wahab O, Pardanani A, Rampal R, Lasho TL, Levine RL, Tefferi A. DNMT3A mutational analysis in primary myelofibrosis, chronic myelomonocytic leukemia and advanced phases of myeloproliferative neoplasms. Leukemia. 2011;25(7): 1219-20.

100. Gowher H, Loutchanwoot P, Vorobjeva O, Handa V, Jurkowska RZ, Jurkowski TP, et al. Mutational analysis of the catalytic domain of the murine Dnmt3a DNA-(cytosine C5)-methyltransferase. J Mol Biol. 2006;357(3):928-41.

101. Challen GA, Sun DQ, Jeong M, Luo M, Jelinek J, Berg JS, et al. Dnmt3a is essential for hematopoietic stem cell differentiation. Nat Genet. 2012;44(1):23-43.

102. Cho YS, Kim EJ, Park UH, Sin HS, Um SJ. Additional sex comb-like 1 (ASXL1), in cooperation with SRC-1, acts as a ligand-dependent coactivator for retinoic acid receptor. J Biol Chem. 2006;281(26):17588-98.

103. Kim K, Choi J, Heo K, Kim H, Levens D, Kohno K, et al. Isolation and characterization of a novel H1.2 complex that acts as a repressor of p53-mediated transcription. J Biol Chem. 2008;283(14):9113-26.

104. Scheuermann JC, de Ayala Alonso AG, Oktaba K, Ly-Hartig N, McGinty RK, Fraterman S, et al. Histone H2A deubiquitinase activity of the Polycomb repressive complex PR-DUB. Nature. 2010;465(7295):243-7.

105. Fisher CL, Pineault N, Brookes C, Helgason CD, Ohta H, Bodner C, et al. Loss-of-function Additional sex combs like 1 mutations disrupt hematopoiesis but do not cause severe myelodysplasia or leukemia. Blood. 2010;115(1):38-46.

106. Abdel-Wahab O, Adli M, Lafave LM, Gao J, Hricik T, Shih AH, et al. ASXL1 mutations promote myeloid transformation through loss of PRC2-mediated gene repression. Cancer Cell. 2012;22(2):180-93.

107. Carbuccia N, Murati A, Trouplin V, Brecqueville M, Adelaide J, Rey J, et al. Mutations of ASXL1 gene in myeloproliferative neoplasms. Leukemia. 2009;23(11):2183-6.

108. Abdel-Wahab O, Manshouri T, Patel J, Harris K, Yao J, Hedvat $\mathrm{C}$, et al. Genetic analysis of transforming events that convert chronic myeloproliferative neoplasms to leukemias. Cancer Res. 2010;70(2):447-52.
109. Stein BL, Williams DM, O'Keefe C, Rogers O, Ingersoll RG, Spivak JL, et al. Disruption of the ASXL1 gene is frequent in primary, post-essential thrombocytosis and post-polycythemia vera myelofibrosis, but not essential thrombocytosis or polycythemia vera: analysis of molecular genetics and clinical phenotypes. Haematologica. 2011;96(10):1462-9.

110. Sauvageau M, Sauvageau G. Polycomb group proteins: multifaceted regulators of somatic stem cells and cancer. Cell Stem Cell. 2010;7(3):299-313.

111. Cao R, Wang L, Wang H, Xia L, Erdjument-Bromage H, Tempst P, et al. Role of histone H3 lysine 27 methylation in Polycomb-group silencing. Science. 2002;298(5595):1039-43.

112. Shen X, Liu Y, Hsu YJ, Fujiwara Y, Kim J, Mao X, et al. EZH1 mediates methylation on histone $\mathrm{H} 3$ lysine 27 and complements EZH2 in maintaining stem cell identity and executing pluripotency. Mol Cell. 2008;32(4):491-502.

113. Margueron R, Li G, Sarma K, Blais A, Zavadil J, Woodcock $\mathrm{CL}$, et al. Ezh1 and Ezh2 maintain repressive chromatin through different mechanisms. Mol Cell. 2008;32(4):503-18.

114. Ernst T, Chase AJ, Score J, Hidalgo-Curtis CE, Bryant C, Jones $\mathrm{AV}$, et al. Inactivating mutations of the histone methyltransferase gene EZH2 in myeloid disorders. Nat Genet. 2010;42(8):722-6.

115. Nikoloski G, Langemeijer SM, Kuiper RP, Knops R, Massop M, Tonnissen ER, et al. Somatic mutations of the histone methyltransferase gene EZH2 in myelodysplastic syndromes. Nat Genet. 2010;42(8):665-7.

116. Morin RD, Johnson NA, Severson TM, Mungall AJ, An J, Goya $\mathrm{R}$, et al. Somatic mutations altering EZH2 (Tyr641) in follicular and diffuse large B-cell lymphomas of germinal-center origin. Nat Genet. 2010;42(2):181-5.

117. Varambally S, Cao Q, Mani RS, Shankar S, Wang X, Ateeq B, et al. Genomic loss of microRNA-101 leads to overexpression of histone methyltransferase EZH2 in cancer. Science. 2008; 322(5908):1695-9.

118. Guglielmelli P, Biamonte F, Score J, Hidalgo-Curtis C, Cervantes F, Maffioli M, et al. EZH2 mutational status predicts poor survival in myelofibrosis. Blood. 2011;118(19):5227-34.

119. Score J, Hidalgo-Curtis C, Jones AV, Winkelmann N, Skinner A, Ward D, et al. Inactivation of polycomb repressive complex 2 components in myeloproliferative and myelodysplastic/myeloproliferative neoplasms. Blood. 2012;119(5):1208-13.

120. Puda A, Milosevic JD, Berg T, Klampfl T, Harutyunyan AS, Gisslinger B, et al. Frequent deletions of JARID2 in leukemic transformation of chronic myeloid malignancies. Am J Hematol. 2012;87(3):245-50.

121. Kralovics R. Genetic complexity of myeloproliferative neoplasms. Leukemia. 2008;22(10):1841-8.

122. Stegelmann F, Bullinger L, Griesshammer M, Holzmann K, Habdank M, Kuhn S, et al. High-resolution single-nucleotide polymorphism array-profiling in myeloproliferative neoplasms identifies novel genomic aberrations. Haematologica. 2010;95(4): $666-9$.

123. Thoennissen NH, Krug UO, Lee DH, Kawamata N, Iwanski GB, Lasho $\mathrm{T}$, et al. Prevalence and prognostic impact of allelic imbalances associated with leukemic transformation of Philadelphia chromosome-negative myeloproliferative neoplasms. Blood. 2010;115(14):2882-90.

124. Scott LM, Scott MA, Campbell PJ, Green AR. Progenitors homozygous for the V617F mutation occur in most patients with polycythemia vera, but not essential thrombocythemia. Blood. 2006;108(7):2435-7.

125. Golub TR, Barker GF, Lovett M, Gilliland DG. Fusion of PDGF receptor beta to a novel ets-like gene, tel, in chronic myelomonocytic leukemia with $\mathrm{t}(5 ; 12)$ chromosomal translocation. Cell. 1994;77(2):307-16. 
126. Odero MD, Carlson K, Calasanz MJ, Lahortiga I, Chinwalla V, Rowley JD. Identification of new translocations involving ETV6 in hematologic malignancies by fluorescence in situ hybridization and spectral karyotyping. Genes Chromosomes Cancer. 2001;31(2):134-42.

127. Banham AH, Beasley N, Campo E, Fernandez PL, Fidler C, Gatter K, et al. The FOXP1 winged helix transcription factor is a novel candidate tumor suppressor gene on chromosome $3 \mathrm{p}$. Cancer Res. 2001;61(24):8820-9.

128. Jager R, Kralovics R. Molecular pathogenesis of Philadelphia chromosome negative chronic myeloproliferative neoplasms. Curr Cancer Drug Targets. 2011;11(1):20-30.

129. Abdulkarim K, Girodon F, Johansson P, Maynadie M, Kutti J, Carli PM, et al. AML transformation in 56 patients with $\mathrm{Ph}-\mathrm{MPD}$ in two well defined populations. Eur J Haematol. 2009;82(2):106-11.

130. Harutyunyan A, Klampfl T, Cazzola M, Kralovics R. p53 lesions in leukemic transformation. N Engl J Med. 2011;364(5):488-90.

131. Veerakumarasivam A, Scott HE, Chin SF, Warren A, Wallard MJ, Grimmer D, et al. High-resolution array-based comparative genomic hybridization of bladder cancers identifies mouse double minute 4 (MDM4) as an amplification target exclusive of MDM2 and TP53. Clin Cancer Res. 2008;14(9):2527-34.

132. Bjorkholm M, Derolf AR, Hultcrantz M, Kristinsson SY, Ekstrand C, Goldin LR, et al. Treatment-related risk factors for transformation to acute myeloid leukemia and myelodysplastic syndromes in myeloproliferative neoplasms. J Clin Oncol. 2011;29(17):2410-5.

133. Osato M, Asou N, Abdalla E, Hoshino K, Yamasaki H, Okubo $\mathrm{T}$, et al. Biallelic and heterozygous point mutations in the runt domain of the AML1/PEBP2alphaB gene associated with myeloblastic leukemias. Blood. 1999;93(6):1817-24.

134. Preudhomme C, Warot-Loze D, Roumier C, Grardel-Duflos N, Garand R, Lai JL, et al. High incidence of biallelic point mutations in the Runt domain of the AML1/PEBP2 alpha B gene in Mo acute myeloid leukemia and in myeloid malignancies with acquired trisomy 21. Blood. 2000;96(8):2862-9.

135. Christiansen DH, Andersen MK, Pedersen-Bjergaard J. Mutations of AML1 are common in therapy-related myelodysplasia following therapy with alkylating agents and are significantly associated with deletion or loss of chromosome arm $7 \mathrm{q}$ and with subsequent leukemic transformation. Blood. 2004;104(5): 1474-81.

136. Harada H, Harada Y, Niimi H, Kyo T, Kimura A, Inaba T. High incidence of somatic mutations in the AML1/RUNX1 gene in myelodysplastic syndrome and low blast percentage myeloid leukemia with myelodysplasia. Blood. 2004;103(6):2316-24.

137. Jager R, Gisslinger H, Passamonti F, Rumi E, Berg T, Gisslinger $\mathrm{B}$, et al. Deletions of the transcription factor Ikaros in myeloproliferative neoplasms. Leukemia. 2010;24(7):1290-8.

138. Kano G, Morimoto A, Takanashi M, Hibi S, Sugimoto T, Inaba $\mathrm{T}$, et al. Ikaros dominant negative isoform (Ik6) induces IL-3independent survival of murine pro-B lymphocytes by activating JAK-STAT and up-regulating Bcl-xl levels. Leuk Lymphoma. 2008;49(5):965-73

139. Truscott M, Harada R, Vadnais C, Robert F, Nepveu A. p110 CUX1 cooperates with E2F transcription factors in the transcriptional activation of cell cycle-regulated genes. Mol Cell Biol. 2008;28(10):3127-38.

140. Cadieux C, Fournier S, Peterson AC, Bedard C, Bedell BJ, Nepveu A. Transgenic mice expressing the p75 CCAATdisplacement protein/Cut homeobox isoform develop a myeloproliferative disease-like myeloid leukemia. Cancer Res. 2006;66(19):9492-501.

141. Vadnais C, Davoudi S, Afshin M, Harada R, Dudley R, Clermont PL, et al. CUX1 transcription factor is required for optimal ATM/ATR-mediated responses to DNA damage. Nucleic Acids Res. 2012;40(10):4483-95.

142. Bollag G, Clapp DW, Shih S, Adler F, Zhang YY, Thompson P, et al. Loss of NF1 results in activation of the Ras signaling pathway and leads to aberrant growth in haematopoietic cells. Nat Genet. 1996;12(2):144-8.

143. Le DT, Kong N, Zhu Y, Lauchle JO, Aiyigari A, Braun BS, et al. Somatic inactivation of Nf1 in hematopoietic cells results in a progressive myeloproliferative disorder. Blood. 2004; 103(11):4243-50.

144. Roug AS, Nyvold CG, Juhl-Christensen C, Christensen M, Schnittger S, Hokland P. A patient with a 20 -year lag phase between JAK2-V617F+ myeloproliferation and NPM1-mutated AML arguing against a common origin of disease. Eur J Haematol. 2011;87(5):461-3.

145. Bellanne-Chantelot C, Chaumarel I, Labopin M, Bellanger F, Barbu V, De Toma C, et al. Genetic and clinical implications of the Val617Phe JAK2 mutation in 72 families with myeloproliferative disorders. Blood. 2006;108(1):346-52.

146. Cario H, Goerttler PS, Steimle C, Levine RL, Pahl HL. The JAK2V617F mutation is acquired secondary to the predisposing alteration in familial polycythaemia vera. $\mathrm{Br} \mathrm{J}$ Haematol. 2005;130(5):800-1.

147. Kralovics R, Stockton DW, Prchal JT. Clonal hematopoiesis in familial polycythemia vera suggests the involvement of multiple mutational events in the early pathogenesis of the disease. Blood. 2003;102(10):3793-6.

148. Pardanani A, Lasho T, McClure R, Lacy M, Tefferi A. Discordant distribution of JAK2V617F mutation in siblings with familial myeloproliferative disorders. Blood. 2006;107(11):4572-3.

149. Rumi E, Passamonti F, Pietra D, Della Porta MG, Arcaini L, Boggi S, et al. JAK2 (V617F) as an acquired somatic mutation and a secondary genetic event associated with disease progression in familial myeloproliferative disorders. Cancer. 2006; 107(9):2206-11.

150. Rumi E, Passamonti F, Della Porta MG, Elena C, Arcaini L, Vanelli L, et al. Familial chronic myeloproliferative disorders: clinical phenotype and evidence of disease anticipation. J Clin Oncol. 2007;25(35):5630-5.

151. Landgren O, Goldin LR, Kristinsson SY, Helgadottir EA, Samuelsson J, Bjorkholm M. Increased risks of polycythemia vera, essential thrombocythemia, and myelofibrosis among 24,577 first-degree relatives of 11,039 patients with myeloproliferative neoplasms in Sweden. Blood. 2008;112(6):2199-204.

152. Harutyunyan AS, Kralovics R. Role of germline genetic factors in MPN pathogenesis. Hematol Oncol Clin N Am. 2012; 26(5):1037-51.

153. El-Harith el-HA, Roesl C, Ballmaier M, Germeshausen M, FryeBoukhriss $\mathrm{H}$, von Neuhoff $\mathrm{N}$, et al. Familial thrombocytosis caused by the novel germ-line mutation p.Pro106Leu in the MPL gene. Br J Haematol. 2009;144(2):185-94.

154. Rumi E, Harutyunyan A, Pietra D, Elena C, Casetti I, Klampfl T, et al. A novel germline JAK2 mutation in familial thrombocytosis. Haematologica 2012;97(s1):244.

155. Mead AJ, Rugless MJ, Jacobsen SE, Schuh A. Germline JAK2 mutation in a family with hereditary thrombocytosis. N Engl $\mathrm{J}$ Med. 2012;366(10):967-9.

156. Olcaydu D, Harutyunyan A, Jager R, Berg T, Gisslinger B, Pabinger I, et al. A common JAK2 haplotype confers susceptibility to myeloproliferative neoplasms. Nat Genet. 2009;41(4): 450-4.

157. Pardanani A, Lasho TL, Finke CM, Gangat N, Wolanskyj AP, Hanson CA, et al. The JAK2 46/1 haplotype confers susceptibility to essential thrombocythemia regardless of JAK2V617F mutational status-clinical correlates in a study of 226 consecutive patients. Leukemia. 2010;24(1):110-4. 
158. Tefferi A, Lasho TL, Patnaik MM, Finke CM, Hussein K, Hogan WJ, et al. JAK2 germline genetic variation affects disease susceptibility in primary myelofibrosis regardless of V617F mutational status: nullizygosity for the JAK2 $46 / 1$ haplotype is associated with inferior survival. Leukemia. 2010;24(1):105-9.

159. Olcaydu D, Rumi E, Harutyunyan A, Passamonti F, Pietra D, Pascutto C, et al. The role of the JAK2 GGCC haplotype and the TET2 gene in familial myeloproliferative neoplasms. Haematologica. 2011;96(3):367-74.
160. Hernandez-Boluda JC, Pereira A, Cervantes F, Alvarez-Larran A, Collado M, Such E, et al. A polymorphism in the XPD gene predisposes to leukemic transformation and new nonmyeloid malignancies in essential thrombocythemia and polycythemia vera. Blood. 2012;119(22):5221-8.

161. Harutyunyan A, Gisslinger B, Klampfl T, Berg T, Bagienski K, Gisslinger $\mathrm{H}$, et al. Rare germline variants in regions of loss of heterozygosity may influence clinical course of hematological malignancies. Leukemia. 2011;25(11):1782-4. 